\title{
MANIFESTAÇÃO DO INSÓLITO ATRAVÉS DO DUPLO NO CONTO O DUPLO, DE COELHO NETO.
}

\author{
Onivaldo Ferreira Coutinho Sobrinho ${ }^{1}$ \\ Naiara Sales Araujo²
}

RESUMO: A literatura maranhense, em linhas gerais, tem sido relativamente lida e analisada no meio acadêmico, sobretudo no tocante a conhecidos nomes como Gonçalves Dias, Aluisio Azevedo, Josué Montello, entre outros. Apesar disso, há alguns gêneros literários, não comumente associados ao Maranhão, ainda carentes de atenção da crítica literária. $O$ gênero Fantástico, por exemplo, que nos remete, a priori, a nomes como Edgar Allan Poe, J.R.R. Tolkien ou C.S. Lewis, foi consideravelmente explorado por autores maranhenses. Nos escritos de Coelho Neto encontramos narrativas que atendem à definição de Todorov (2007) do fantástico, como é o caso do conto O Duplo (1927), objeto de análise deste trabalho cujo objetivo visa a analisar a presença do Insólito, a partir dos apontamentos sobre o duplo nas narrativas fantásticas. Para tanto, utilizaremos os estudos de críticos como Todorov (2007), Flavio García (2007) Keppler (1976), dentre outros.

PALAVRAS-CHAVE: Insólito. Fantástico. Duplo. Coelho Neto

\section{INTRODUÇÃO}

O presente trabalho foi concebido a partir do interesse por pesquisas em Estudos Literários, principalmente aquelas relacionadas à autores maranhenses. Ao estudar o chamado gênero literário Fantástico, despertou-se o interesse em produzir uma análise do conto O Duplo (1927), de Coelho Neto, já que a literatura maranhense está relativamente presente no cenário nacional, mas pouco se tem estudado no que diz respeito ao discurso fantástico. Assim, a análise do evento sobrenatural, chamado de duplo, presente no conto como elemento insólito, mostrou-se um possível ponto de partida para verificar como este e outros elementos são utilizados no discurso fantástico de Coelho Neto.

O conceito mais lido e citado para e sobre o discurso Fantástico foi proposto por Todorov em seu livro Introdução à literatura fantástica (2007). Sua premissa básica é de que o discurso Fantástico só acontece quando há o sentimento de hesitação na narrativa, este que consiste em não encontrar uma explicação para um evento que irrompe com a coerência que até então a narrativa

\footnotetext{
${ }^{1}$ Graduando e PIBIC do curso de Letras - UFMA. Email: onixfcs@gmail.com

2 Professora Doutora da Universidade Federal do Maranhão _UFMA. Email: naiara.sas@gmail.com
} 
desenrolava. Essa hesitação precisa ocorrer num mundo familiar ao do leitor, para que então ela o atinja.

Neste artigo apresentaremos os conceitos inerentes ao insólito como o responsável pelo rompimento da coerência narrada sob a ótica conceitual do pesquisador Flávio García (2007), para então apresentar o conceito de duplo a partir do pesquisador americano Carl Francis Keppler em sua obra The literature of the second self (1976). Também lançaremos mão dos apontamentos complementares da espanhola Rebeca Martín Lopez em seu estudo Las manifestaciones del doble en La narrativa breve española contemporânea (2006), bem como dos apontamentos de Todorov (2007). Objetiva-se, aqui, analisar como o discurso Fantástico de Coelho Neto se apresenta no conto O Duplo (1927) tendo como base as leituras teóricas sobre gênero Fantástico.

\section{O FANTÁSTICO E O ELEMENTO INSÓLITO}

Para Todorov (2007), o que transcende de fato o Fantástico na literatura é o sentimento de hesitação, caraterística essencial para o gênero Fantástico. Assim, Todorov diz que esse gênero é resultante de "[...] um acontecimento que não pode ser explicado pelas leis deste mesmo mundo familiar" (2007, p.30). Nesse sentido, tem-se um ocorrido sem explicação, que passeia pela linha tênue entre o real e o imaginário, o concreto e o insólito, que trazem o sentimento de hesitação entre uma explicação natural e uma sobrenatural. Dessa forma, o Fantástico é o gênero literário que nos remete à sensação de não conseguir encontrar uma explicação lógica ou racional para um determinado acontecimento.

Sabe-se que para a classificação de uma narrativa dentro do gênero literário fantástico, ela precisa seguir três assertivas. A primeira, que traz a essencial presença do sentimento de hesitação entre uma explicação sobrenatural ou natural para a narrativa. A segunda é a relação entre personagem e leitor, que ocorre quando a hesitação sentida pelo personagem também passa pelo leitor e, por sua vez, a terceira assertiva é a não aceitação de uma possível interpretação poética ou alegórica. Assim, a narrativa necessita de elementos inexplicáveis ou fatos que causem algum tipo de estranhamento. 
Para Todorov (2007), a hesitação seria o marco de uma narrativa de gênero Fantástico, pois é essa ambiguidade não conclusiva, que balança entre o natural e o sobrenatural, que para ele, traz a característica central de uma narrativa fantástica. Entretanto, esse acontecimento extraordinário não pode receber um fato que o explique, até que a narrativa tenha seu fim. Caso contrário, ela perderá, o que para o autor supracitado, é a raiz para se consolidar uma narrativa entre os preceitos que o gênero Fantástico preestabelece.

O crítico literário italiano Remo Cesarini (2006) afirma a importância do sentimento de hesitação e do acontecimento extraordinário inexplicável para as narrativas fantásticas, quando diz:

\begin{abstract}
O conto fantástico envolve fortemente o leitor, leva-o pra dentro de um mundo a ele familiar, aceitável, pacífico, para depois fazer disparar os mecanismos da surpresa, da desorientação, do medo: possivelmente um medo percebido fisicamente, como ocorre em textos pertencentes a outros gêneros e modalidades, que são exclusivamente programados para suscitar no leitor longos arrepios na espinha, contrações, suores. (CESERANI, 2006, p. 71)
\end{abstract}

O medo, então, torna-se um componente fundamental para o gênero Fantástico. Este passa a ser um pressuposto para que o evento insólito se desenrole. Assim, o medo se alimenta do desconhecido ou do extraordinário causando no leitor o sentimento de hesitação em busca de uma explicação para o fato que ocorre.

Por sua vez, Todorov (2007) nos remete a uma linha de raciocínio que demarca o campo do gênero Fantástico. Ele afirma que a narrativa precisa acontecer sob o trabalho de leis naturais familiares ao leitor, para que então seja notório o acontecimento sobrenatural. Este precisa permanecer no campo do desconhecido e deixar a hesitação existente até o fim da narrativa. Neste sentido:

Somos assim transportados ao âmago do fantástico. Num mundo que é exatamente o nosso, aquele que conhecemos, sem diabos, sílfides nem vampiros, produz-se um acontecimento que não pode ser explicado pelas leis deste mesmo mundo familiar. Aquele que o percebe deve optar por uma das soluções possíveis; ou se trata de uma ilusão dos sentidos, de um produto da imaginação e nesse caso as leis do mundo continuam a ser o que são; ou então o acontecimento realmente ocorreu, é parte integrante da realidade, mas nesse caso esta realidade é regida por leis desconhecidas para nós. (...) O fantástico ocorre nesta incerteza; ao escolher uma ou outra resposta, deixa-se o fantástico para entrar num gênero vizinho, o estranho ou o maravilhoso. O fantástico é a hesitação experimentada por um ser que só conhece as leis naturais, face a um acontecimento aparentemente sobrenatural. (TODOROV, 2007 p.30-31) 
A citação acima nos remete ao campo do insólito, do acontecimento extraordinário e sobrenatural que submerge num mundo real e comum, regido por leis naturais conhecidas, sendo esse fato algo que não possa ser explicado por tais leis que regem o ambiente e o mundo do personagem. É neste terreno incerto em que o fato estranho da narrativa ocorre, sendo responsável por criar a atmosfera da hesitação, veementemente defendida por Ceserani:

\begin{abstract}
Várias vezes encontramos, nos contos fantásticos que lemos, exemplos de passagem da dimensão do cotidiano, do familiar e do costumeiro para a do inexplicável e do perturbador: passagem de limite, por exemplo da dimensão da realidade para a do sonho, do pesadelo, ou da loucura. $O$ personagem protagonista se encontra repentinamente como se estivesse dentro de duas dimensões diversas [...]. (2006, p.73)
\end{abstract}

Tal descrição pode ser encontrada no conto O Duplo (1927), objeto de nossa análise. Em meio à vida cotidiana, seguindo sem nenhum desvio aparente, ocorre o fato inexplicável e extraordinário na obra de Coelho Neto. A narrativa inicia com um diálogo entre dois amigos próximos nomeados como Benito Soares e "O coronel". O evento é narrado pelo protagonista com o intuito de que seu amigo desembarace os maus pensamentos que rodeavam sua, agora então, paranoica mente. $O$ desfecho da história é quase uma paráfrase da premissa de Todorov a respeito da relação entre o sentimento de hesitação e o discurso fantástico.

É possível considerar que o insólito é algo que anda no campo do extraordinário. O seu efeito na narrativa também é passível de alguns caminhos que dependem do aspecto cultural, regional ou temporal do leitor. Segundo o pesquisador Flávio García, tem-se que:

Insólito abarca aquilo que não é habitual, o que é desusado, estranho, novo, incrível, desacostumado, inusitado, pouco frequente, raro, surpreendente, decepcionante, frustrante, o que rompe com as expectativas da naturalidade e da ordem, a partir do senso comum, representante de um discurso oficial hegemônico. (2012, p. 1)

Seguindo uma perspectiva que trata do insólito como um elemento do fantástico, podemos aferir que tal elemento é parte fundamental para este gênero. Assim, constata-se que o insólito tem papel de criar um cenário fantástico defendido por Todorov, a hesitação. Neste sentido, podemos considerar o momento da aparição do duplo no conto de Coelho neto, como o fator 
extraordinário que deixa às claras a sensação de hesitação. Ainda seguindo os apontamentos de García, constata-se que:

Assim, eventos insólitos presentes nas narrativas do gênero Fantástico são questionados pelos seres de papel sem que se encontrem respostas aceitáveis para o seu questionamento. Esses eventos acabam prisioneiros da razão e da lógica, postos à prova interminavelmente. (2012, p. 2)

Ainda nessa perspectiva, García traz uma assertiva muito pertinente sobre o insólito que, se atrelado ao conto analisado, trará a confirmação de que o que ocorreu com o personagem passou pelo crivo das premissas do que seria um evento insólito. Segundo ele:

Assim, os eventos insólitos seriam aqueles que não são frequentes de acontecer, são raros, pouco costumeiros, inabituais, inusuais, incomuns, anormais, contrariam o uso, os costumes, as regras e as tradições, enfim, surpreendem ou decepcionam o senso comum, às expectativas quotidianas correspondentes a dada cultura, a dado momento, a dada e específica experienciação da realidade (2007, p. 20)

É ainda possível inserir, como fruto do evento insólito que ocorre no conto, a sua responsabilidade por causar a hesitação no narrador, que transcreverá a sua ambiguidade e a ausência de uma explicação natural, agindo como uma extensão para que o mesmo ocorra com o leitor. É o que Flávio García afirma em $A$ construção do insólito ficcional e sua leitura literária: procedimentos instrucionais da narrativa:

[...] a dúvida, a insegurança e a hesitação do narrador, fazendo daquele seu cúmplice na fragilidade das (in)certezas narradas. Assim, a sensação de estar travando contato com o insólito chega ao narratário e, portanto e por extensão, aos leitores. (2009, p. 3-4)

Em outras palavras, o insólito pode ser aquele elemento imprescindível ao evento que não seja comum, rotineiro, natural ao ambiente, mas que traga divergência significativa frente ao natural, seja no aspecto sobrenatural, cultural ou temporal.

\section{O DUPLO EM COELHO NETO}

A obra $O$ duplo, do escritor maranhense Henrique Maximiano Coelho Neto (1864-1934), fora escrita e publicada em 1927 junto aos demais contos da 
obra Contos de vida e de morte. Coelho Neto ficou conhecido pela academia como "O príncipe dos Prosadores Brasileiros" e teve um grande espaço no cenário da literatura pós-moderna, um feito alcançado por poucos na mesma época. Ele era personagem atuante em causas sociais, dando jus ao seu codinome. O Maranhense passou boa parte da sua vida no Rio de Janeiro, cidade que foi cenário de algumas de suas obras. No período chamado de Belle Époque, foi um dos grandes momentos para o escritor, já que o seu estilo cativou a elite cultural da época.

$O$ conto é narrado em forma de diálogo entre dois personagens com menção de alguns outros não tão importantes. A conversa é feita entre o "Coronel" amigo do protagonista e quem vivenciou o fato, Benito Soares. Envolve de início o desconforto sobre o ocorrido, quando Benito ouve do seu amigo coronel, que Laura, sua esposa, foi quem contou para ele e para outros da vizinhança o seu caso de desdobramento como ele mesmo menciona.

Benito segue a narrativa expressando sua hesitação na busca por uma explicação sobrenatural a partir do místico religioso, ao mesmo tempo em que desconfia de sua sanidade mental. A narrativa então começa a demarcar as premissas defendidas por Todorov (2007), nas falas dos personagens. Quando Benito diz "- Não sei que foi. Digo-te apenas que passei os minutos mais angustiosos da minha vida." (COELHO NETO, 1927), remete-nos ao que diz Todorov a respeito do evento fantástico "Um acontecimento que não pode ser explicado pelas leis deste mesmo mundo familiar" (TODOROV, 2007).

Não raro encontramos a figura do duplo em narrativas literária. Talvez não exagero afirmar que desde os tempos mais remotos, percorrendo a história literária, partindo da mitologia, passando por outras manifestações artísticas, temos a presença do Duplo como elemento insólito. A pesquisadora Ana Maria Lisboa de Mello ambientar-nos-á com uma perfeita colocação sobre o que seria o Duplo:

[...] o fenômeno do duplo surge como representação de uma cisão interna. Revela-se seguidamente como uma experiência inquietante, em que o sujeito se vê como outro ou em face de um ser com quem muito se parece. Esse encontro pode provocar angústia, mal-estar e medo, nem sempre passíveis de equacionar. Pode significar também o encontro necessário para solucionar a divisão interna e levar ao alcance da unidade [...]. (2000, p.121-122) 
Seguindo a premissa dada por Mello (2000), entraremos agora no campo de classificação para este fenômeno. O pesquisador Carl Francis Keppler traz uma divisão de sete tipos de duplo na obra The literature of the second self (1970). Este autor defende que o Duplo é responsável por causar um sentimento ambíguo, podendo atrair ou repulsar, ocorrendo no momento da narrativa em que a personagem esteja com a guarda baixa ou em um estado de fragilidade.

Para Keppler, as sete representações do Duplo são: o perseguidor, o gêmeo, o (a) bem-amado (a), o tentador, a visão de horror, o salvador e o duplo no tempo (1970, p.55). Ele aborda o perseguidor como sendo um monstro, um animal feroz, uma imagem no espelho ou até mesmo a briga entre gêmeos, na qual existe força bruta e aniquilação advinda de uma possível traição entre eles. O duplo tentador busca levar o seu duplicado a autodestruição por meio da persuasão, o "pai da mentira" (1970, p. 56). Para o autor supracitado, o duplo de visão de horror, em que podemos encaixar o conto analisado de Coelho Neto, não é de natureza animalesca ou perversa. Entretanto, ver a própria morte, o seu próprio corpo estático, inerte, como no conto, é a pior visão de horror (1970, p. 78) para o ser humano.

O duplo não é necessariamente mal, ele também pode se inclinar para o lado protetor agindo como um guarda costas ou salvador. No caso do duplo bemamado, há uma atração mútua, contudo suas características opostas geram a desestabilidade das ações. $O$ duplo no tempo aborda uma duplicidade no espaço e tempo, ou seja, há uma transição entre espaços temporais podendo o sujeito entrar em conflito com sua noção de presente, passado e futuro ou estar presente neles simultaneamente.

Nesta mesma perspectiva, a pesquisadora Rebeca Lopez argumenta que: "El doble aparece cuando dos incorporaciones del mismo personaje coexiste ne nun mismo espacio o mundo ficcional ${ }^{3}$." ( 2006, p.18.). Com esse conceito, temos que o desdobramento sofrido pelo personagem na narrativa de Coelho Neto (1927) se encaixa nos parâmetros de duplo, tanto na visão de Keppler (1976), como visão de horror de Lopez (2006), já que temos a existência de dois seres no

${ }^{3} \mathrm{O}$ duplo aparece quando duas figurações do mesmo personagem coexistem em um mesmo espaço ou mundo fictício [tradução nossa]. 
mesmo espaço, onde um assiste o seu eu inerte, em equilíbrio apenas por estar sentado entre duas pessoas obesas, imprensado, de forma grosseira.

Neste sentido, López sugere uma premissa explicativa sobre um caso de duplo, o qual reforça a nossa análise "El protagonista, por lo general asistente a sus propias exequias, se contempla a si mismo muerto ${ }^{4}$. " (2006, p.18.). É possível, através da afirmação de Lopez (2006), ambientar-nos no ocorrido com o personagem, que diante de seu corpo parado, dado como morto em seu evento insólito assiste a si mesmo como um defunto em meio de duas pessoas que ainda não notaram seu "falecimento". O protagonista imagina que é dado como morto e está sendo levado ao cemitério e então, como duplo, é plateia do próprio funeral. Isso ocorre através da dissociação corpo/espirito, e o segundo desassociado da sua matéria corpórea, contempla-a como o duplo.

Por fim, temos em López (2006), duas explicações para a relação do Duplo com o Fantástico. A primeira, diz que é natural o confronto que existe com o Duplo nas narrativas Fantásticas, que seria o duelo entre a vertente do real e a do sobrenatural (essas dualidades estão presentes no alicerce para o evento do duplo: é através de sua manifestação que temos o confronto entre o personagem real e o duplo). Em sua segunda assertiva, temos uma quebra na sequência natural da narrativa. É nesse momento em que, pelo fantástico, acontece a irrupção do evento insólito, ou seja, um corte na ordem natural e racional (esse corte é representado, no fantástico, pela irrupção do insólito e, por conseguinte no duplo, através do desdobramento do personagem, que aos olhos da ciência tem de ser inexplicável.

Nesta mesma perspectiva, López (2006) acrescenta que um papel extra para o duplo na narrativa fantástica é de desmascarar o ser em seu aspecto moral e social. Trazendo à tona partes ocultas de sua personalidade, deixando as claras suas fragilidades, medos e angústias, que são perceptíveis quando o personagem do conto entra em desespero ao imaginar-se assistindo seu próprio funeral.

$\mathrm{Na}$ tentativa de dividir com alguém sua inquietação, Benito ainda apreensivo, solta nua e cruamente o que lhe ocorreu no bonde pela manhã:

$$
\text { - Viste...? - (Coronel) }
$$

\footnotetext{
${ }^{4} \mathrm{O}$ protagonista geralmente acompanha de seu próprio funeral, e contempla-se morto [ tradução nossa].
} 
- A mim mesmo, a mim! Eu, eu em pessoa sentado defronte de mim, no banco da frente, que dá costas à plataforma. Era eu, eu! Como refletido em um espelho, e certo estremeci vivamente, incomodando os meus companheiros laterais, porque ambos voltaram-se encarando-se de má sombra." (COELHO NETO, 1927)

O sentimento de hesitação que surge na narrativa transpassa para 0 leitor. É nesse momento que o fantástico toma conta do ambiente e nada permanecerá como verdade e nenhuma explicação poderá ser encontrada, para que as premissas Todorovianas permaneçam presentes.

Como comentado no corpo deste trabalho, para Flávio García, "os eventos insólitos seriam aqueles que não são frequentes de acontecer, são raros, pouco costumeiros, inabituais, inusuais, incomuns [...]" (2007, p.20), que então se demonstra na narrativa:

- [...] Pasmado, sem poder desfitar os olhos daquele reflexo, que era, em tudo, eu: nas feições, na atitude, no trajo, não parecido, mas reproduzido em exteriorização, pensei de mim comigo. (COELHO, 1927)

É então no ponto seguinte da fala, que Benito Soares acopla seu acontecimento à definição de Duplo dada por Ana Maria Mello. O personagem conta o seu evento, como uma experiência pós-morte:

- Se tal se dá é que o meu espírito, alma, ou lá o que seja, exalou-se de mim, deixando-me apenas o corpo, como a borboleta deixa o casulo em que se opera a metamorfose. Assim, pois, o que ali se achava, no bonde, era uma massa inerte, sustida pelos dois corpanzis que ladeavam. E, em menos de um segundo, vi todo o horror da cena, que seria cômica, se não fosse trágica, que se daria com a retirada de um daqueles gordos." (COELHO, 1927)

É nessa parte da narrativa que vemos o já comentado duplo visão de horror, classificado assim pelo pesquisador americano Keppler quando ele diz que: "Ver a própria morte, o seu próprio corpo estático, inerte, é a pior visão de horror" (1970, p.78). Em seguida, Coelho Neto deixa a demarcação do conto no discurso fantástico:

- Teria descido? Não! Não descera. Tornara a mim, atraído pela vontade, na ânsia de viver, no desespero em que me vi, só comparável ao de alguém que, indo ao fundo, sem saber nadar, debate-se agoniadamente conseguindo elevar-se à tona e gritar a socorro. E tudo isso, meu amigo, não durou, talvez, um minuto e eu guardo de tais instantes a impressão penosa de um século de sofrimento.

- Essas coisas, meu amigo, não se explicam: registam-se, são observações, fatos, elementos para a Ciência do Futuro, que será, talvez, Ciência da Verdade." (COELHO, 1927) 
Neste trecho, Coelho Neto deixa claro sua intenção e escolha em deixar o fato permanecer inexplicável, presenteando o leitor com um conto tão fantástico quanto criterioso para os padrões do gênero.

\section{CONSIDERÇAÇÕES FINAIS}

É possível constatar que a obra estudada nesse artigo apresenta um discurso fantástico desenvolvido pelo evento insólito do Duplo. Esse acontecimento é responsável por todo o desenrolar da trama conferindo assim nossa suspeita inicial de que a obra se enquadra nos padrões pré-estabelecidos de gênero fantástico.

O elemento Duplo é o que traz todo o contexto de um ambiente fantástico para a narrativa trabalhada, sendo também responsável por causar a sensação de hesitação tão comentada por Todorov. Assim, podemos dizer que o conto se insere no discurso fantástico pela inserção de alguns elementos que trazem à tona o questionamento de serem reais ou irreais e permanecem sem explicação até o final da trama.

Por fim, é importante salientar que apesar de tantas obras em gêneros diferentes, o discurso fantástico de Coelho Neto reitera o quão grande era o seu inventário narrativo. $\mathrm{O}$ autor soube cadenciar em poucas páginas uma narrativa dentro dos padrões do gênero Fantástico, presenteando o leitor com um intrigante e surpreendente desfecho.

\section{REFERÊNCIAS}

CESERANI, Remo (2006). O fantástico. Curitiba: Ed. UFPR.

COELHO NETO, Henrique Maximiano (1927). O duplo. Disponível em: <http://www.biblio.com.br/defaultz.asp?link=http://www.biblio.com.br/conteudo/Co elhoNeto/oduplo.htm>. Acesso em: 15 set. 2016.

GARCIA, Flavio. O Insolito na Narrativa Ficcional: a questão e os conceitos na teoria dos generos literarios. In: A Banalizacao do Insolito: Questoes de Genero Literario - Mecanismos de Construcao Narrativa. /Flavio Garcia (org.) - Rio de Janeiro: Dialogarts, 2007. (Versao digitalizada) 
. (2012). A banalização do insólito na narrativa de ficção como marca distintiva de um outro e novo gênero literário, o insólito banalizado: as tensões entre a questão do insólito e os conceitos que dela tentam dar conta na literatura da lusofonia - Brasil, Portugal, Galícia. Disponível em:

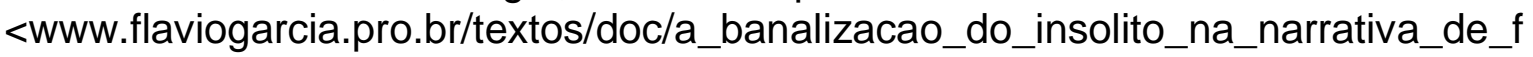
iccao_com_marcas_distintivas.pdf>. Acesso em: 16 set. 2016.

KEPPLER, Carl Francis (1976). The literature of the second self. Arizona: The University of Arizona Press.

LÓPEZ, Rebeca Martín (2006). Las manifestaciones del doble en La narrativa breve española contemporanea. Tese de Doutorado. Departamento de Filología Española, Universidad Autónoma de Barcelona, Barcelona.

MELLO, Ana Maria Lisboa de (2000). "As faces do duplo na literatura". In: INDURSKY, Freda \& CAMPOS, Maria do Carmo. (Orgs.). Discurso, memória, identidade. Porto Alegre: Sagra Luzzato. p.111-123.

TODOROV, Tzvetan (2007). Introdução à literatura fantástica. São Paulo: Perspectiva. 